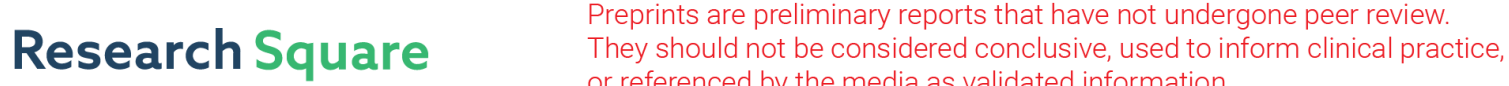 or referenced by the media as validated information. \\ Intratumor Bacterial Presence and Serum Amyloid A in Colorectal Cancer
}

\section{Greta M Waal}

Stellenbosch University

\section{Willem JS Villiers}

Stellenbosch University

Jonathan Rigby

Stellenbosch University

\section{Timothy Roberts}

University College London Hospital NHS Foundation Trust

Etheresia Pretorius ( $\square$ resiap@sun.ac.za )

Stellenbosch University

\section{Research Article}

Keywords: Intratumor bacterial presence, serum amyloid, colorectal cancer

Posted Date: April 13th, 2021

DOl: https://doi.org/10.21203/rs.3.rs-403105/v1

License: (c) (1) This work is licensed under a Creative Commons Attribution 4.0 International License. Read Full License 


\section{Abstract}

\section{Background \& Aims:}

The initiation, development, and progression of many cancers, including colorectal cancer (CRC), are associated with environmental factors. A significant link exists between specific bacterial infections and cancer incidence, with a strong association between chronic infection, chronic inflammation and colorectal carcinogenesis. Recently, we reported significantly increased levels of lipopolysaccharide in CRC patient blood, compared to that of healthy individuals. By analysing CRC tumors, this study aims to contribute to the identification of (novel) markers/factors associated with CRC tumorigenesis.

Methods: Colorectal tumor samples from newly diagnosed (histologically confirmed) CRC patients $(\mathrm{n}=$ $24)$ and morphologically normal colon biopsies $(n=10)$ were collected and analysed in a cross-sectional study. Immunohistochemistry protocols and statistical signal analysis were used to detect specific bacteria and proteins of interest in human colorectal tissue. Furthermore, the presence of structural protein changes in CRC tumor tissues, compared to control tissues, was investigated using the fluorescent amyloidselective Amytracker ${ }^{\mathrm{TM}} 630$ marker and confocal microscopy.

Results: We show an intratumor bacterial presence in CRC patients, with high levels of Escherichia coli strongly associated with CRC. High levels of intratumor serum amyloid A are also strongly associated with CRC. Furthermore, Helicobacter pylori is elevated, but to a smaller degree, and only when we account for data imbalance. We also report a significantly enhanced amyloid-specific fluorescence signal in CRC tumors, compared to control tissues.

Conclusions: The role that infections play in a variety of cancers, including CRC, is increasingly recognized, and we provide evidence of a bacterial presence in CRC tumors. The analysis of CRC tumors, in addition to CRC blood, offers unique opportunities to investigate factors that may fuel colorectal carcinogenesis, and to ultimately identify novel markers that are associated with CRC.

\section{Introduction}

Patients diagnosed with advanced stages of colorectal cancer (CRC) have a poor prognosis (low 5-year survival rates) ${ }^{1,2}$, with increased incidence and mortality of CRC among young adults being prevalent ${ }^{3}$. $\mathrm{CRC}$ is a heterogeneous disease with various contributing factors involved in the carcinogenic process, including exogenous factors (environmental insults) and endogenous factors (genetic susceptibility) ${ }^{4}$ (see Fig. 1). The immune system, intestinal microbiota, environmental and lifestyle risk factors, as well as genetic factors are all involved in the pathogenesis of $\mathrm{CRC}{ }^{5}$. The vast majority of $\mathrm{CRC}$ cases are sporadic and non-inherited ${ }^{6-8}$, which necessitates further investigation regarding environmental risk factors, including microbial exposures. Importantly, emphasis has again recently been placed on the human tumor microbiome across several cancer types ${ }^{9}$. 
The intestinal microflora provides protection against pathogens and has homeostatic immune and metabolic functions ${ }^{10}$. A breakdown of the physiological balance in the gut flora composition can lead to changes in the local immune system, causing pathology ${ }^{11}$. The involvement of disruptive changes in the gut microbiota balance (gut dysbiosis) in the pathogenesis of several chronic inflammatory pathologies, including cancers such as CRC, is currently a main research focus ${ }^{2,12-14}$. Importantly, a significant interaction exists between the intestinal microbiota and CRC pathogenesis, with the immune system playing a central role in this cross-talk ${ }^{14}$.

When the ratio of protective to pro-inflammatory and pro-tumorigenic microflora becomes deregulated, it can lead to intestinal inflammation via persistent immune dysregulation ${ }^{10,11}$. Chronic inflammatory responses result in a cascade of events, where secreted inflammatory mediators can influence neoplastic development, cell proliferation, metastasis, and angiogenesis, thereby creating a unique pro-neoplastic or tumor-supporting microenvironment ${ }^{15,16}$. Chronic inflammation thus increases the risk for the development of CRC ${ }^{17,18}$, forming a major part of CRC tumorigenesis ${ }^{19-21}$. However, a bidirectional relationship exists between the gut microbiota and the immune system: gut dysbiosis affects host immunity, but mucosal immunity can also in turn modulate the microbiota ${ }^{14}$.

Chronic inflammation in the tumor microenvironment triggers and promotes tumor growth and invasion, angiogenesis, and metastasis ${ }^{22,23}$. Immune cells are actively involved in the inflammatory process, where immune cell infiltrates produce pro-tumorigenic inflammatory cytokines and chemokines ${ }^{10,24}$. Cytokines and chemokines may act as tumor growth/survival factors by promoting angiogenesis and by suppressing immune-mediated tumor elimination ${ }^{10}$. Immune cells in the tumor microenvironment, together with their secreted growth factors and various signaling molecules, therefore play important roles in promoting the proliferation and survival of tumor cells, and in driving tumor progression ${ }^{25,26}$. In $\mathrm{CRC}$, the activation of specific transcription factors, the production of inflammatory cytokines and chemokines, and leukocyte infiltration are all factors contributing to the pathology of chronic inflammation 27.

An inflammatory tumor microenvironment thus accelerates tumor progression (malignant transformation and invasion) ${ }^{21,23,26}$. However, sporadic CRCs are also accompanied by tumor-elicited inflammation ${ }^{28}$. Cancer cells synthesize and release factors that can fuel the neoplastic process, by recruiting more inflammatory cells and stimulating the inflammatory cascade ${ }^{25}$. Importantly, during tumor progression, bacteria and microbial products can invade the local tumor environment as a result of damage to the epithelial barrier. These barrier defects result in tumor-induced inflammation, stimulated by the invasion of bacteria ${ }^{29}$. A bacterial presence in tumors can therefore promote and accelerate the progression of $\mathrm{CRC}^{29}$.

This paper will investigate the presence of bacteria (the Gram-negative bacteria Helicobacter pylori $(H$. pylori) and Escherichia coli (E. coli )) and the bacterial inflammagen lipopolysaccharide (LPS) in the local tumor environment of CRC patients, compared to healthy colorectal tissue biopsies. It is well-known that 
H. pylori can colonize the gastro duodenal mucosa of humans ${ }^{30}$. An association exists between $H$. pylori infection and gastric adenocarcinoma, with $H$. pylori infection also being a risk factor for mucosaassociated lymphoid tissue (MALT) lymphoma ${ }^{30}$. Interestingly, there is also likely an association between $H$. pylori infection and CRC risk, but causality remains uncertain ${ }^{31}$. This therefore served as the rationale for the detection of $H$. pylori in CRC tumor tissue samples.

Furthermore, the presence of another inflammatory marker, serum amyloid A (SAA), which is associated with the presence of bacterial products such as LPS, will also be investigated in CRC tumors, compared to control tissues. Importantly, elevated levels of the acute-phase (multifunctional) protein SAA serve as a sensitive marker for acute and chronic inflammatory diseases and have been implicated in colorectal carcinogenesis ${ }^{25}$. In addition, structural changes in proteins associated with CRC tumor cells and/or their microenvironment, using a fluorescent amyloidselective marker, will be investigated. When normally soluble proteins undergo a (amyloidogenic) pathological configurational change and become misfolded, aggregate, and form fibrils, they become insoluble (resistant to normal proteolytic digestion) $25,32,33$. The extracellular deposition of such amyloid $\beta$-pleated sheet fibrils is associated with several chronic (ongoing) inflammatory disease states ${ }^{32}$.

The impact of environmental factors on CRC initiation, development, and progression, represents a growing research field 7,8 . The aim of this paper is to demonstrate, by analysing CRC tumors, that an intratumor bacterial presence, together with the presence of inflammatory markers/mediators (specifically SAA) and structural protein changes, are involved in CRC tumor pathogenesis.

\section{Methods}

\section{Ethical statement}

Ethical clearance for the collection of stored normal colorectal tissue biopsies from healthy individuals (serving as control tissues), as well as tumor tissues from patients with newly diagnosed colorectal adenocarcinoma was obtained from the Health Research Ethics Committee (HREC) of Stellenbosch University (ethics reference: 6585). All study participants signed an informed consent form prior to participation in the study and sample collection. This study, including sample collection and sample processing, was conducted according to the guidelines set by the Declaration of Helsinki.

\section{Sample collection and study population}

Table 1 shows the sample demographics of healthy and CRC populations. Formalin-fixed, paraffinembedded (FFPE) morphologically normal colon biopsies from 10 healthy individuals and FFPE colorectal tumor resections $(n=18)$ and biopsies $(n=6)$ from 24 patients with newly diagnosed (histologically confirmed) colorectal adenocarcinoma were collected from the National Health Laboratory Service at Tygerberg Hospital, Cape Town, South Africa. The stage of all recruited patients was assessed, with stage $1(n=1)$, stage $2(n=10)$, stage $3(n=8)$, and stage $4(n=5)$ CRC patients included. The American 
Joint Committee on Cancer/Union for International Cancer Control (AJCC/UICC) 8th edition staging system was used to assess the stage of patients who had tumor resections, while CT scans were used to assess the stage of patients who had biopsies taken. None of the CRC patients had any cancer treatment at the time of sample collection (no neoadjuvant chemotherapy or radiotherapy). Genetic predisposition did not form part of the exclusion criteria.

Table 1. Demographic information of healthy individuals and colorectal cancer (CRC) patients.

\begin{tabular}{|lll|}
\hline \multicolumn{2}{|l|}{ Demographics } \\
& Healthy individuals & CRC patients \\
\hline Gender & Male $(n=5)$, Female $(n=5)$ & Male $(n=11)$, Female $(n=13)$ \\
\hline Age (years) & $60.5[37.75-69.25]$ & $55.5[44-68.5]$ \\
\hline
\end{tabular}

Data expressed as median and [25\% - 75\% quartile range].

\section{Tissue preparation}

An automated tissue processer (Tissue-Tek ${ }^{\circledR}$ VIP ${ }^{\text {TM }}$ Vacuum Infiltration Processor) was used for tissue processing, which runs for a total time of \pm 12 hours according to the protocol in Supplementary Table S1. Following sectioning of blocks (using the Leica RM 2125 rotary microtome (SMM instruments, Germany)), tissue sections were transferred to a water bath and placed onto standard microscope slides for haematoxylin and eosin (H\&E) staining, or positively charged microscope slides for immunohistochemistry and for confocal analysis. Prior to staining, slides were incubated at approximately $60^{\circ} \mathrm{C}$ for about one hour for the removal of wax. Ultimately, following staining of the sections, a glass coverslip was mounted onto the tissue using distyrene, a plasticizer, and xylene (DPX) mounting media and left to dry for 48 hours (Dako fluorescence mounting medium was used for confocal analysis).

\section{Haematoxylin and eosin (H\&E) staining}

To study the morphology and structure of healthy colorectal tissues and CRC tumor tissues, the H\&E stain was used to stain tissue sections. Slides were placed into a plastic staining rack, which was placed into the Leica Auto Stainer XL (SMM instruments, Germany). The autostainer follows a pre-programmed procedure, including steps for the deparaffinisation, rehydration, and clearing of the tissue (see Supplementary Table S2). Zeiss Axioskop 2 Microscope (Carl Zeiss, Germany) was used to view the slides and examine staining, with Zen Lite software (v2.3, Germany) used to capture the images.

\section{Immunohistochemistry}

All immunohistochemical staining procedures were performed on the BOND-MAX automated system (Leica, Wetzlar, Germany), using the Bond Polymer Refine Detection System (Leica Bond ${ }^{\mathrm{TM}}$ ) (Cat no. 
DS9800). An automated immunohistochemical staining protocol was used, including a standard dewax (using Bond Dewax Solution (Leica Bond ${ }^{\mathrm{TM}}$ ) (Cat no. AR9222)) and rehydrate program, as well as pretreatment for antigen retrieval. Refer to Table 2 for the automated staining protocol. Tissues were either incubated in Bond Epitope Retrieval (ER) Solution 2 (Leica Bond ${ }^{\mathrm{TM}}$ ) (Cat no. AR9640) or Bond ER Solution 1 (Leica Bond ${ }^{\mathrm{TM}}$ ) (Cat no. AR9961), prior to incubation with the primary antibody. Following a wash step (standard wash protocol with Bond Wash Solution (Leica Bond ${ }^{\mathrm{TM}}$ ) (Cat no. AR9590)), endogenous peroxidases in tissue sections were blocked. After incubation with the primary antibody, the chromogen diaminobenzidine (DAB) was used to visualize positive antibody-antigen reactions, and counterstained with haematoxylin to observe tissue morphology. Following completion of automated staining, the samples were dehydrated (refer to Supplementary Table S3). Zeiss Axio Observer 7 inverted Microscope (Carl Zeiss, Germany) with Axiocam 305 colour camera, using the brightfield modality and 5x objective, was used to view the slides and examine staining.

Immunohistochemical protocols were developed and optimized to detect the proteins of interest in the tissue samples. The following antibodies were used: anti-H. pylori antibody, anti-E. coli antibody, anti-E. coli LPS antibody, and anti-SAA antibody. The optimal dilution factor of each antibody (step 9 in Table 2) (all antibodies were diluted in Bond Primary Antibody Diluent (Leica Bond ${ }^{\mathrm{TM}}$ ) (Cat no. AR9352)) and the optimal ER buffer in each case (step 3 in Table 2) were optimized. Positive (tissue) controls for H. pylori, E. coli, LPS, and SAA were used to confirm that each antibody binds to its specific immunogen. Negative antibody controls were also included. Negative and positive control images are shown in Supplementary Fig. S1-S4. Zeiss Axioskop 2 Microscope (Carl Zeiss, Germany) was used to view these control slides and examine staining, with Zen Lite software (v2.3, Germany) used to capture the images.

To detect $H$. pylori in tissue sections, Anti-Helicobacter pylori antibody [EPR10353] (rabbit monoclonal IgG, ab172611, Abcam) was used (diluted 1:250). ER1 buffer was used for heat-induced epitope retrieval (HIER). H. pylori human gastritis tissue (from a stomach biopsy), as recommended by the antibody datasheet, was used as a positive tissue control. For detection of E. coli, E. coli serotype 0157 Monoclonal Antibody (I88H) (mouse monoclonal IgG, MA1-7303, Invitrogen) was used (diluted 1:100), using ER2 buffer. For a positive control, healthy platelet poor plasma (PPP) was exposed to a colony of $E$. coli cells (E. coli ATCC 13706). The Cytospin ${ }^{\circledR} 3$ Cell Preparation System was used to deposit a monolayer of cells in a defined area onto a microscope slide, using centrifugal force. A volume of $150 \mu \mathrm{L}$ of the exposed PPP sample was added to the sample chamber, and centrifuged at a speed of $2000 \mathrm{rpm}$ for 3 minutes. To detect bacterial LPS in tissue sections, Anti-E. coli LPS antibody [2D7/1] (mouse monoclonal lgG, ab35654, Abcam) was used (diluted 1:100), using ER2 buffer. Rat intestinal tissue, as recommended by the antibody datasheet, was used as a positive tissue control. To detect SAA in tissues, immuno-purified rabbit anti-human SAA antibody (kindly provided by Prof. Frederick C. de Beer and Dr. Marcielle de Beer from the University of Kentucky), with a concentration of $4.1 \mathrm{mg} \mathrm{mL}^{-1}$, was used (diluted 1:1500), using ER1 buffer. Human tonsil tissue was used as a positive tissue control.

Table 2. Automated immunohistochemical staining protocol. 


\begin{tabular}{|c|c|c|c|c|}
\hline \multicolumn{2}{|c|}{ Step } & \multirow{2}{*}{$\begin{array}{l}\text { Reagent } \\
\text { Standard bake }\end{array}$} & \multirow{2}{*}{$\begin{array}{l}\text { Time } \\
30 \\
\text { minutes }\end{array}$} & \multirow{2}{*}{$\begin{array}{l}\text { Temperature } \\
60^{\circ} \mathrm{C}\end{array}$} \\
\hline 1 & Bake & & & \\
\hline 2 & Dewax, rehydrate & $\begin{array}{l}\text { Bond Dewax Solution, } 100 \% \text { ethanol and } \\
\text { deionized water }\end{array}$ & & \\
\hline 3 & Antigen retrieval & ER1 or ER2 buffer & $\begin{array}{l}20 \\
\text { minutes }\end{array}$ & $100^{\circ} \mathrm{C}$ \\
\hline 4 & Wash & Bond Wash Solution & $\begin{array}{l}0 \\
\text { minutes }\end{array}$ & \\
\hline 5 & $\begin{array}{l}\text { Block endogenous } \\
\text { peroxidase }\end{array}$ & $\begin{array}{l}\text { Peroxide block (from Bond Polymer Refine } \\
\text { kit) }\end{array}$ & $\begin{array}{l}5 \\
\text { minutes }\end{array}$ & $23^{\circ} \mathrm{C}$ \\
\hline 6 & Wash & Bond Wash Solution & $\begin{array}{l}0 \\
\text { minutes }\end{array}$ & \\
\hline 7 & & Bond Wash Solution & $\begin{array}{l}0 \\
\text { minutes }\end{array}$ & \\
\hline 8 & & Bond Wash Solution & $\begin{array}{l}0 \\
\text { minutes }\end{array}$ & \\
\hline 9 & $\begin{array}{l}\text { Primary antibody } \\
\text { binding }\end{array}$ & $\begin{array}{l}\text { Primary antibody diluted in Bond Primary } \\
\text { Antibody Diluent }\end{array}$ & $\begin{array}{l}15 \\
\text { minutes }\end{array}$ & $23^{\circ} \mathrm{C}$ \\
\hline 10 & Wash & Bond Wash Solution & $\begin{array}{l}0 \\
\text { minutes }\end{array}$ & \\
\hline 11 & & Bond Wash Solution & $\begin{array}{l}0 \\
\text { minutes }\end{array}$ & \\
\hline 12 & & Bond Wash Solution & $\begin{array}{l}0 \\
\text { minutes }\end{array}$ & \\
\hline 13 & $\begin{array}{l}\text { Detection of bound } \\
\text { antibody }\end{array}$ & $\begin{array}{l}\text { Post Primary (from Bond Polymer Refine } \\
\text { kit) }\end{array}$ & $\begin{array}{l}8 \\
\text { minutes }\end{array}$ & $23^{\circ} \mathrm{C}$ \\
\hline 14 & & Bond Wash Solution & $\begin{array}{l}2 \\
\text { minutes }\end{array}$ & \\
\hline 15 & & Bond Wash Solution & $\begin{array}{l}2 \\
\text { minutes }\end{array}$ & \\
\hline 16 & & Bond Wash Solution & $\begin{array}{l}2 \\
\text { minutes }\end{array}$ & \\
\hline 17 & & Polymer (from Bond Polymer Refine kit) & $\begin{array}{l}8 \\
\text { minutes }\end{array}$ & $23^{\circ} \mathrm{C}$ \\
\hline 18 & Wash & Bond Wash Solution & $\begin{array}{l}2 \\
\text { minutes }\end{array}$ & \\
\hline 19 & & Bond Wash Solution & $\begin{array}{l}2 \\
\text { minutes }\end{array}$ & \\
\hline
\end{tabular}




\begin{tabular}{|c|c|c|c|c|}
\hline 20 & & Deionized water & $\begin{array}{l}0 \\
\text { minutes }\end{array}$ & \\
\hline 21 & & Deionized water & $\begin{array}{l}0 \\
\text { minutes }\end{array}$ & \\
\hline 22 & Colour development & DAB (from Bond Polymer Refine kit) & $\begin{array}{l}10 \\
\text { minutes }\end{array}$ & $23^{\circ} \mathrm{C}$ \\
\hline 23 & Wash & Deionized water & $\begin{array}{l}0 \\
\text { minutes }\end{array}$ & \\
\hline 24 & & Deionized water & $\begin{array}{l}0 \\
\text { minutes }\end{array}$ & \\
\hline 25 & & Deionized water & $\begin{array}{l}0 \\
\text { minutes }\end{array}$ & \\
\hline 26 & Counterstain & $\begin{array}{l}\text { Haematoxylin (from Bond Polymer Refine } \\
\text { kit) }\end{array}$ & $\begin{array}{l}5 \\
\text { minutes }\end{array}$ & \\
\hline 27 & Wash & Deionized water & $\begin{array}{l}0 \\
\text { minutes }\end{array}$ & \\
\hline 28 & & Deionized water & $\begin{array}{l}0 \\
\text { minutes }\end{array}$ & \\
\hline 29 & & Deionized water & $\begin{array}{l}0 \\
\text { minutes }\end{array}$ & \\
\hline
\end{tabular}

To simplify automated imaging of the tissue randomly positioned on the different slides, a block was drawn around each tissue section to fully encompass the outer boundaries of the specific section. The coordinates of the four corners of this box shaped perimeter were then used to set up a tile scan in the Zen Pro software (v2.5, Germany). The software automatically calculated the number of images to acquire to scan the complete section. Importantly, tiles containing artefacts were excluded from analysis, as well as tiles containing no tissue in the field of view. About 97 tile images were analysed per CRC tumor tissue sample, and \pm 11 tile images per healthy colorectal tissue sample. The stitching function of the analyses section of the Zen software, which allows for the correct alignment of the tiles to view a complete section, was applied. However, only the individual tiles were used for statistical analyses. The intensity and exposure time settings were $8.3 \%$ and 0.08 seconds, respectively.

\section{Confocal analysis for the detection of structural protein changes}

In order to investigate structural protein changes present in healthy colorectal tissues and CRC tumor tissues, tissue sections were incubated with the amyloid-selective Amytracker ${ }^{\mathrm{TM}} 630$ marker (Ebba Biotech $A B$ ). Tissue sections were either stained with only the fluorescent amyloidogenic marker, or with both Amytracker ${ }^{\mathrm{TM}} 630$ and Hoechst fluorescent dye (supplied at $10 \mathrm{mg} \mathrm{mL}^{-1}$ (Sigma)). First, tissue sections were deparaffinised (refer to Supplementary Table S4) and fixed with ice-cold ethanol (95\%) for 
5 minutes at room temperature. Following rehydration of the tissue sections in a mix of ethanol and deionized water (1:1) for 5 minutes, sections were equilibrated in Gibco ${ }^{\text {TM }}$ phosphate-buffered saline (PBS) $(\mathrm{pH}=7.4)$ (ThermoFisher Scientific, 11594516) for 5 minutes. For staining with only the Amytracker ${ }^{\mathrm{TM}} 630$ marker, tissue sections were subsequently incubated in Amytracker ${ }^{\mathrm{TM}} 630$ (diluted 1:1000 in PBS) for 30 minutes, followed by PBS wash steps ( $2 \times 5$ minutes). In cases where tissue sections were also stained with Hoechst fluorescent dye, following this wash step, tissue sections were incubated in Hoechst dye (diluted 1:200 in PBS) for 5 minutes and then further washed in PBS (3x5 minutes). Single stained and unstained samples were included for method development and optimization of staining of tissue sections with both Amytracker ${ }^{\mathrm{TM}} 630$ and Hoechst dye. A Zeiss LSM 780 with ELYRA PS1 confocal microscope with a Plan-Apochromat 20x/0.8 objective was used to view the slides.

The following settings were used:

- Staining with only Amytracker ${ }^{\mathrm{TM}}$ 630: $488 \mathrm{~nm}$ excitation laser, with emission measured at 606-695 $\mathrm{nm}$

- Staining with Amytracker ${ }^{\mathrm{TM}} 630$ and Hoechst fluorescent dye:

1. Amytracker ${ }^{\text {TM }}$ 630: $488 \mathrm{~nm}$ excitation laser, with emission measured at 606-695 nm

2. Hoechst fluorescent dye: $405 \mathrm{~nm}$ excitation laser, with emission measured at $415-460 \mathrm{~nm}$

For data acquisition and comparison between healthy colorectal tissue and CRC tumor tissue images, gain settings were kept constant to ensure a reliable statistical outcome. All micrographs were captured in an unbiased manner as $3 \times 3$ tile images. At least 4 tile images were captured per sample stained with Amytracker $^{\text {TM }}$ 630. Of 4 healthy colorectal tissue samples, 17 images were acquired, with 23 images acquired from 4 CRC tumor tissue samples. The mean fluorescence intensity (MFI) of all acquired images was computed (using Image $(\mathrm{FIJI})^{34}$ ) to compare the response to the Amytracker ${ }^{\mathrm{TM}} 630$ marker in control tissues and CRC tumor tissues. In addition, unstained healthy colorectal tissue samples and unstained CRC tumor tissue samples were analysed to account for the autofluorescence of the tissues. A minimum of 2 tile images were captured per unstained sample. The average MFI of the corresponding unstained CRC tumor tissue samples was subsequently subtracted from the individual MFI values of the CRC tumor tissue samples stained with Amytracker $^{\text {TM }}$ 630. The same approach applied to the healthy colorectal tissue samples.

\section{Statistical analysis}

The immunohistochemistry signal was analysed in the following straightforward manner. 1D colour histograms for each of the four antibody signals were formed based on manually identified regions across multiple images. These histograms are shown in Figure 7A. These (normalized) histograms were then applied across each image to determine a total signal strength. A logistic statistical model (using $\mathrm{glm}$ in R 4.0.2) was then applied to determine the strength of association (and confidence intervals) between the signal strength and disease status. As the dynamic range of the signal is very large, a log 
transform was performed to the signal strength. Odds Ratios are reported on the log scale after z-score standardisation to allow meaningful comparison between stains. Lastly, as the datasets were imbalanced, with more disease images than control images, we performed an additional analysis with inverse frequency weighting of the logistic loss. Results are consistent between these weighted and unweighted models with the exception of $\mathrm{H}$. pylori, where we make more conservative claims. The unweighted model does not account for the imbalance regarding the number of control tissue and CRC tumor tissue samples, and also not for the imbalance in the number of images per sample, while the weighted model accounts for these data imbalances (making it unbiased).

Data of the confocal analysis were tested for normality using the Shapiro-Wilk normality test, and analysed using the Mann-Whitney non-parametric test in GraphPad Prism 7.04 (the image plot of the confocal data was prepared in GraphPad Prism 7.04). Statistical significance was accepted at $p<0.05$.

\section{Results}

\section{Patho-morphology of colorectal cancer (CRC) tumor tissues}

Figure 2 compares two (labelled) micrographs of healthy colorectal and CRC tumor tissues stained with $\mathrm{H} \& \mathrm{E}$. The different tissue layers can be distinguished in healthy colorectal tissues and normal mucosa demonstrates a regular architecture (Fig. 2A). However, the architecture of CRC tumors is haphazard, disordered and infiltrating (Fig. 2B). Malignant glands are disorganized and have inconsistent shapes and sizes. Glands of the mucosa are normally lined with cuboidal/columnar cells with well-ordered nuclei (orientated towards the base). However, since tumor cells are rapidly proliferating, their nuclei appear at different levels (have a pseudostratified appearance), are larger, and have an irregular arrangement. Additional micrographs of H\&E stains of healthy colorectal tissues (Supplementary Fig. S5-S6) and CRC tumor tissues (Supplementary Fig. S7-S8) are also shown.

\section{The presence of an intratumor bacterial component and inflammatory marker}

Representative tile images of (A) healthy colorectal tissue biopsies and (B) CRC tumor tissues stained with anti-H. pylori antibody (Fig. 3), anti-E. coli antibody (Fig. 4), anti-E. coli LPS antibody (Fig. 5), and anti-SAA antibody (Fig. 6) are shown. Also refer to Supplementary Fig. S9-S12 for tile images that are stitched together of (A) healthy colorectal tissue biopsies and (B) CRC tumor tissues, stained with anti- $H$. pylori antibody, anti-E. coli antibody, anti-E. coli LPS antibody, and anti-SAA antibody, respectively.

Refer to Fig. 7A for 1D colour histograms of manually extracted positive signal for each of the four antibodies. The areas identified as positive signal for the anti-E. coli LPS antibody and anti-SAA antibody deliver normally distributed histograms with clear peaks for all channels. However, the H. pylori signal and $E$. coli signal are less normally distributed than the signal of the anti-E. coli LPS and anti-SAA antibodies. Figure 7B shows box and whisker plots that compare the log signal present in healthy colorectal tissues and CRC tumor tissues, stained with anti-H. pylori antibody, anti-E. coli antibody, anti-E. 
coli LPS antibody, and anti-SAA antibody, respectively. Table 3 indicates the Odds Ratios and confidence intervals (for the unweighted and weighted models) of the log signal for each antibody.

Table 3. Odds Ratios (OR) and confidence intervals $(\mathrm{Cl})$ of the log signal for the respective antibodies. Antibody signals with a significant difference between control and disease populations at the $95 \%$ level are shown in bold.

\begin{tabular}{|lllll|}
\hline \multirow{2}{*}{ Antibody } & \multicolumn{2}{l}{ Unweighted } & \multicolumn{2}{l|}{ Weighted } \\
\cline { 2 - 5 } & OR & $95 \% \mathrm{Cl}$ & OR & $95 \% \mathrm{Cl}$ \\
\hline Anti-H. pylori & 1.15 & $0.95-1.38$ & 1.14 & $1.07-1.22$ \\
\hline Anti-E. coli & 1.18 & $1.05-1.33$ & 1.24 & $1.18-1.30$ \\
\hline Anti-E. coli LPS & 0.97 & $0.88-1.07$ & 0.98 & $0.95-1.01$ \\
\hline Anti-SAA & 1.12 & $1.02-1.22$ & 1.20 & $1.15-1.25$ \\
\hline
\end{tabular}

It can be seen that both the E. coli and SAA signals are significantly elevated in CRC tumor tissues, compared to healthy colorectal tissues (this finding is consistent in both unweighted and weighted models). It is important to note that, when the data is weighted, high levels of both E. coli and SAA have an even stronger association with CRC. The findings for $H$. pylori, on the other hand, are not consistent across the unweighted and weighted models and the effect size is smaller. When looking at the unweighted result, there is no significant difference in the $H$. pylori signal between healthy colorectal tissues and CRC tumor tissues. However, when the data is weighted (when the data imbalance is accounted for), the $H$. pylori signal becomes significantly elevated in the disease population. High levels of $H$. pylori are therefore also associated with CRC, but to a smaller degree than E. coli and SAA. This is in line with the general understanding that $H$. pylori is predominantly present in the antrum of the stomach and the proximal duodenum. Lastly, there is no significant difference in the bacterial LPS signal between healthy colorectal tissues and CRC tumor tissues.

\section{Structural protein changes in colorectal cancer (CRC) tumor tissues}

Structural protein changes were investigated by staining healthy colorectal tissue biopsies and CRC tumor tissues with the fluorescent amyloidogenic Amytracker ${ }^{\mathrm{TM}} 630$ marker. Amytracker ${ }^{\mathrm{TM}}$ binds to and stains classical amyloid protein structures (protein aggregates) ${ }^{35,36}$. Representative confocal micrographs of (a) healthy colorectal and (b) CRC tumor tissues stained with Amytracker ${ }^{\mathrm{TM}} 630$ are shown in Fig. 8A. Refer to Supplementary Fig. S13 for additional confocal micrographs of the amyloidspecific fluorescence signal in (A) healthy colorectal tissues and (B) CRC tumor tissues, together with the corresponding transmitted light images. It is clear that the fluorescence amyloid signal in CRC tumor tissues is more concentrated, while the fluorescence signal in healthy colorectal tissues is dispersed and 
dim. Figure 8B compares the distribution of the MFIs in a scatterplot, indicating that CRC tumor tissues contain significantly greater amyloid-specific signal, compared to healthy colorectal tissues.

Additionally, in order to visualize the structure of the tissue sections in combination with the amyloidspecific fluorescence signal, two healthy colorectal tissue samples and two CRC tumor tissue samples were stained with Hoechst fluorescent dye and the amyloid-selective Amytracker ${ }^{\mathrm{TM}} 630$ marker. In this way, the nuclei of the tissues were stained, and could be visualized together with the amyloid-specific signal present in the tissue sections (refer to Supplementary Fig. S14 for confocal micrographs and corresponding transmitted light images).

\section{Discussion}

We have previously analysed CRC patient blood and reported that circulating levels of LPS are significantly elevated in the CRC population, compared to controls ${ }^{37}$. The aim of this study was to analyse the local tumor environment of these patients (to describe CRC tumor physiology), to identify factors that are involved in CRC tumor pathogenesis. Refer to Fig. 9 for an overview of the findings of CRC patient blood sample and tumor tissue analyses.

The tumor physiology of CRC patients was analysed by first investigating the patho-morphology of CRC tumor tissues. A clear difference was observed in the structure and appearance of cells when comparing normal colorectal tissues to CRC tumor tissues, by using the H\&E stain. This is as a result of aberrations in cell proliferation and differentiation in cancer patients ${ }^{38}$. Within the lumen of malignant glands, mucin and (granular) necrotic material were frequently observed. CRC is often associated with dirty necrosis within glandular lumina ${ }^{39}$. There was also an overproduction of mucin in some tumors, with excess mucin infiltrating the stroma. Importantly, mucin is involved in the metastatic process of CRC ${ }^{40}$. The tumor stroma is also an important role player in tissue invasion and in driving tumor progression ${ }^{41,42}$. It has been suggested that a reduction of the epithelial cells/stroma (E/S) ratio may serve as indication of tumor progression (a poor prognosis) in CRC patients ${ }^{42}$. The desmoplastic stromal reaction observed in CRC tumors is associated with a poor prognosis in these patients ${ }^{43,44}$. Furthermore, the host antitumor immune response affects tumor progression and recurrence ${ }^{45}$. The type, location and density of tumorinfiltrating immune cells give an indication of the clinical outcome or prognosis of CRC patients ${ }^{46}$.

The presence of bacteria in CRC tumor tissues (focusing on the Gram-negative bacteria $H$. pylori and $E$. coli), compared to healthy colorectal tissues, was also investigated in this paper. Importantly, there is a significant link between specific bacterial infections and cancer incidence ${ }^{47,48}$. Streptococcus bovis, $H$. pylori, E. coli, Fusobacterium nucleatum, and enterotoxigenic Bacteroides fragilis (ETBF) are particular bacterial species that are associated with $\mathrm{CRC}^{49}$. H. pylori infection may be implicated in CRC pathogenesis, as it has been reported that $H$. pylori infection can increase the risk of CRC ${ }^{50-52}$. Positive associations between $H$. pylori infection and an increased CRC occurrence have also been shown ${ }^{53-55}$. However, there is not a clear causal relationship between $H$. pylori infection and the development of CRC 
$31,56,57$. The hypothesis that by-products of $H$. pylori infection may increase the risk of CRC, is supported by findings showing that increased serum levels of gastrin (hypergastrinemia) are positively associated with an increased risk of CRC ${ }^{57-59}$. Hypergastrinemia may be involved in CRC pathogenesis by inducing increased cell proliferation in the colonic mucosa ${ }^{60}$. It is therefore possible that $H$. pylori infection itself is not the only factor implicated in an increased CRC risk, which highlights the complex (and less established) relationship between H. pylori and CRC ${ }^{57}$. The results of this paper showed that, when accounting for the imbalance in the data, high levels of $H$. pylori are associated with CRC, but have a small effect size.

Mucosa-adherent $E$. coli, a commensal bacteria forming part of the human gut microbiota, is strongly associated with CRC ${ }^{61-65}$. Table 3 confirms that the presence of $E$. coli is significantly elevated in CRC tumor tissues, compared to control tissues. Certain E. coli strains contain virulence genes and can cause pathology ${ }^{66}$. Some pathogenic E. coli strains have DNA mutagenesis capabilities (acquired pathogenicity islands) and can interfere with DNA repair processes, ultimately contributing to disease induction ${ }^{8,67}$. The genotoxic $E$. coli phylogenetic group $\mathrm{B} 2$ harbours the polyketide synthase $(p k s)$ island that is responsible for synthesizing a peptide-polyketide hybrid genotoxin named colibactin, which enables $E$. colito induce DNA damage, thereby participating in colorectal carcinogenesis ${ }^{15,67,68}$. The majority of $E$. coli isolated from CRC patients contains this genotoxic island (has genotoxic capabilities) 69,70. It has been shown that $E$. coli can induce colon inflammation and promote cell proliferation in a chronic infection model ${ }^{70}$. Moreover, E. coli can trigger Wnt-mediated signaling pathways, which are frequently mutated or enhanced in CRC ${ }^{8,15}$. E. coli is therefore considered as an important role player in CRC development ${ }^{14}$, being frequently associated with colorectal tumors ${ }^{7}$.

A significantly modified intestinal microbiota composition is evident in CRC patients, compared to controls, with an increased diversity of Gram-negative bacteria subgroups being present ${ }^{71}$. LPS is a very potent inflammagen and an essential component of the outer membrane of Gram-negative bacteria ${ }^{72}$. This bacterial antigen induces innate immunity and can cause intestinal inflammation when recognized by toll-like receptor $4^{10}$, with this signaling pathway being actively involved in the metastatic cascade ${ }^{73}$. Table 3 indicates that there is no significant difference in the presence of LPS between control tissues and CRC tumor tissues. However, LPS plays a role in lymph node metastasis, with lymph node metastatic CRC tissues having higher concentrations of LPS than none lymph node metastasis CRC tissues ${ }^{72}$. Furthermore, we showed that high levels of intratumor SAA are strongly associated with CRC. The local expression of SAA mRNA and protein in human colon adenocarcinomas has been demonstrated previously, with tumor cells being the main SAA expressing cells ${ }^{74}$. Moreover, a meta-analysis indicated that elevated levels of SAA in human solid tumors are significantly related to poor overall survival (or poor prognosis) in cancer patients ${ }^{75}$. It has also been proposed that SAA has an impact on tumor aggressiveness ${ }^{76}$. SAA can lead to the degradation of the extracellular matrix (ECM) ${ }^{74}$, which can contribute to tumor initiation and development ${ }^{25}$. SAA may lead to ECM alterations by stimulating the expression and synthesis of matrix metalloproteinases (MMPs) (MMPs are implicated in ECM 
degradation and angiogenesis) ${ }^{25,77}$. SAA also contains binding sites for components of the ECM, laminin and heparin/heparan sulfate 25,74 . The role of SAA as an ECM adhesion protein contributes to its proposed role in tumorigenesis 25,74 .

We therefore showed that there is an intratumor bacterial presence and (upregulated) expression of SAA in CRC tumor tissues. It is well-known that inflammatory factors such as circulating LPS cause an increase in the hepatic production of SAA, resulting in elevated circulating levels of SAA ${ }^{78,79}$. Although the expression of SAA in extrahepatic tissues (tissue-derived SAA proteins) is associated with cancer progression ${ }^{78}$, the link between the presence of LPS and SAA in CRC tumor tissues is not established. Even though no significant difference in LPS levels between control tissues and CRC tumor tissues was reported, we hypothesise that there might also be an association between the presence of LPS and the expression of SAA in CRC tumor tissues (especially considering that high levels of LPS are present in lymph node metastatic CRC tissues).

Lastly, a fluorescent amyloid-selective marker was used to visualize structural protein changes in CRC tumor tissues. The amyloid-specific fluorescence signal was significantly enhanced in CRC tumor tissues, compared to healthy colorectal tissues, suggesting that more misfolded protein structures/aggregates are present in CRC tumor tissues. Importantly, protein unfolding ultimately results in the production of non-native species, often forming protein aggregates ${ }^{80}$. In native proteins, hydrophobic bonds are located within their tertiary structure. Following protein unfolding, the formation of inter-molecular hydrophobic bonds leads to the formation of aggregates, being resistant to catalytic hydrolysis ${ }^{80}$. The amyloid form of a protein can be more stable than the native conformation of the protein molecule ${ }^{81}$. This means that the native state of such proteins does not contain the lowest free energy ${ }^{82}$. Protein misfolding and protein aggregates are associated with a variety of human disorders, including neurodegenerative diseases and type 2 diabetes ${ }^{81,83}$. The misfolding and aggregation of the tumorsuppressor protein p53 may also be implicated in cancer pathogenesis ${ }^{83}$.

\section{Conclusions}

When the physiological balance of the gut microbial composition becomes compromised, it may result in a pro-inflammatory environment, contributing to the development of $\mathrm{CRC}^{84}$. This supports the view that the onset of many cancers, including CRC, is associated with environmental or external factors ${ }^{6}$. We have recently analysed the systemic environment of CRC patients, where circulating LPS and other circulating biomarkers, indicative of systemic inflammation and abnormal clot formation, were investigated. A main finding was that elevated circulating LPS levels are predictive of an increased chance of $\mathrm{CRC}^{37}$. Here, we demonstrated that there is an intratumor bacterial presence in CRC patients, showing that high levels of $E$. coli are strongly associated with CRC, and that $H$. pylori is also significantly elevated in CRC tumor tissues, compared to healthy colorectal tissues. Importantly, we also showed that the presence of high levels of intratumor SAA is strongly associated with CRC. 
The development of novel, non-invasive, sensitive, and specific early detection methods (such as tumor biomarkers), together with early diagnosis and effective treatment strategies, are pivotal to minimize and manage the vast number of individuals affected by CRC ${ }^{19}$. To study the local tumor environment of CRC patients, in combination with analysing their systemic environment, offers unique opportunities for the identification of novel markers that are associated with CRC. We conclude that the heterogeneity of CRC necessitates the employment of holistic approaches when investigating colorectal carcinogenesis, to improve our overall understanding of the disease.

\section{Declarations}

\section{Data Availability}

The datasets analysed for this study can be found on Google Drive: https://drive.google.com/drive/folders/1sOcsKTQabwx-HcvpkG6gt7eKMysl-w-V?usp=sharing.

\section{Acknowledgements}

We thank the National Research Foundation (NRF) of South Africa (91548: Competitive Program) and the Medical Research Council of South Africa (MRC) (Self-Initiated Research Program: A0X331) for supporting this collaboration. The funders had no role in study design, data collection and analysis, decision to publish, or preparation of the manuscript. Timothy Roberts is funded by the NIHR UCLH Biomedical Research Centre. We would also like to thank Mr Reggie Williams, for his assistance with the histology work.

\section{Author contributions}

GdW did the analysis and interpretation of data, performed the literature search and designed the figures; WdV edited the text; JR helped with sample collection and also edited the text; TR did the statistical analysis and edited the text; EP, as corresponding author, edited the text.

\section{Additional information}

The authors declare no competing interests.

\section{References}

1. Worm Ørntoft, M. B. Review of Blood-Based Colorectal Cancer Screening: How Far Are Circulating Cell-Free DNA Methylation Markers From Clinical Implementation? Clin. Colorectal Cancer. 17, e415e433 https://doi.org/10.1016/j.clcc.2018.02.012 (2018).

2. Villéger, R. et al. Microbial markers in colorectal cancer detection and/or prognosis. World journal of gastroenterology. 24, 2327-2347 https://doi.org/10.3748/wjg.v24.i22.2327 (2018). 
3. Bhandari, A., Woodhouse, M. \& Gupta, S. Colorectal cancer is a leading cause of cancer incidence and mortality among adults younger than 50 years in the USA: a SEER-based analysis with comparison to other young-onset cancers. Journal of investigative medicine: the official publication of the American Federation for Clinical Research. 65, 311-315 https://doi.org/10.1136/jim-2016000229 (2017).

4. Aran, V., Victorino, A. P., Thuler, L. C. \& Ferreira, C. G. Colorectal Cancer: Epidemiology, Disease Mechanisms and Interventions to Reduce Onset and Mortality. Clin. Colorectal Cancer. 15, 195-203 https://doi.org/10.1016/j.clcc.2016.02.008 (2016).

5. Park, C. H., Eun, C. S. \& Han, D. S. Intestinal microbiota, chronic inflammation, and colorectal cancer. Intestinal research. 16, 338-345 https://doi.org/10.5217/ir.2018.16.3.338 (2018).

6. Grivennikov, S. I., Greten, F. R. \& Karin, M. Immunity, inflammation, and cancer. Cell. 140, 883-899 https://doi.org/10.1016/j.cell.2010.01.025 (2010).

7. Faïs, T., Delmas, J., Cougnoux, A., Dalmasso, G. \& Bonnet, R. Targeting colorectal cancer-associated bacteria: A new area of research for personalized treatments. Gut microbes. 7, 329-333 https://doi.org/10.1080/19490976.2016.1155020 (2016).

8. Drewes, J. L., Housseau, F. \& Sears, C. L. Sporadic colorectal cancer: microbial contributors to disease prevention, development and therapy. British journal of cancer. 115, 273-280 https://doi.org/10.1038/bjc.2016.189 (2016).

9. Nejman, D. et al. The human tumor microbiome is composed of tumor type-specific intracellular bacteria. Science (New York, N.Y.). 368, 973 https://doi.org/10.1126/science.aay9189 (2020).

10. Terzić, J., Grivennikov, S., Karin, E. \& Karin, M. Inflammation and Colon Cancer. Gastroenterology. 138, 2101-21142105 https://doi.org/10.1053/j.gastro.2010.01.058 (2010).

11. DuPont, A. W. \& DuPont, H. L. The intestinal microbiota and chronic disorders of the gut. Nature reviews Gastroenterology \& hepatology. 8, 523 (2011).

12. Zackular, J. P. et al. The Gut Microbiome Modulates Colon Tumorigenesis. mBio. 4, e00692-00613 https://doi.org/10.1128/mBio.00692-13 (2013).

13. Cogdill, A. P., Gaudreau, P. O., Arora, R., Gopalakrishnan, V. \& Wargo, J. A. The Impact of Intratumoral and Gastrointestinal Microbiota on Systemic Cancer Therapy. Trends in Immunology. 39, 900-920 https://doi.org/10.1016/j.it.2018.09.007 (2018).

14. Cianci, R. et al. The interplay between immunity and microbiota at intestinal immunological niche: The case of cancer. International journal of molecular sciences. 20, https://doi.org/10.3390/ijms20030501 (2019).

15. Raskov, H., Burcharth, J. \& Pommergaard, H. C. Linking Gut Microbiota to Colorectal Cancer. Journal of Cancer. 8, 3378-3395 https://doi.org/10.7150/jca.20497 (2017).

16. Cario, E. Microbiota and innate immunity in intestinal inflammation and neoplasia. Current opinion in gastroenterology. 29, 85-91 https://doi.org/10.1097/MOG.0b013e32835a670e (2013).

17. Ullman, T. A. \& Itzkowitz, S. H. Intestinal Inflammation and Cancer. Gastroenterology. 140, 1807$1816(2011)$. 
18. Arthur, J. C. et al. Intestinal inflammation targets cancer-inducing activity of the microbiota. Science (New York, N. Y.). 338, 120-123 https://doi.org/10.1126/science.1224820 (2012).

19. Zhang, X. et al. The potential role of ORM2 in the development of colorectal cancer. PloS one. 7, e31868-e31868 https://doi.org/10.1371/journal.pone.0031868 (2012).

20. Remiker, A. S. \& Palumbo, J. S. Mechanisms coupling thrombin to metastasis and tumorigenesis. Thromb. Res. 164, S29-S33 https://doi.org/10.1016/j.thromres.2017.12.020 (2018).

21. Mantovani, A., Allavena, P., Sica, A. \& Balkwill, F. Cancer-related inflammation. Nature. 454, 436 https://doi.org/10.1038/nature07205 (2008).

22. O'Toole, A. et al. Tumour microenvironment of both early- and late-stage colorectal cancer is equally immunosuppressive. British Journal of Cancer. 111, 927-932 https://doi.org/10.1038/bjc.2014.367 (2014).

23. Lin, W. W. \& Karin, M. A cytokine-mediated link between innate immunity, inflammation, and cancer. The Journal of clinical investigation. 117, 1175-1183 https://doi.org/10.1172/JCl31537 (2007).

24. Kraus, S. \& Arber, N. Inflammation and colorectal cancer. Current Opinion in Pharmacology. 9, 405410 https://doi.org/10.1016/j.coph.2009.06.006 (2009).

25. Malle, E., Sodin-Semrl, S. \& Kovacevic, A. Serum amyloid A: an acute-phase protein involved in tumour pathogenesis. Cellular and molecular life sciences: CMLS. 66, 9-26 https://doi.org/10.1007/s00018-008-8321-x (2009).

26. Kostic, A. D., Chun, E., Meyerson, M. \& Garrett, W. S. Microbes and inflammation in colorectal cancer. Cancer immunology research. 1, 150-157 https://doi.org/10.1158/2326-6066.CIR-13-0101 (2013).

27. Erreni, M., Mantovani, A. \& Allavena, P. Tumor-associated Macrophages (TAM) and Inflammation in Colorectal Cancer. Cancer Microenvironment. 4, 141-154 https://doi.org/10.1007/s12307-010-00525 (2011).

28. Long, A. G., Lundsmith, E. T. \& Hamilton, K. E. Inflammation and Colorectal Cancer. Current colorectal cancer reports. 13, 341-351 https://doi.org/10.1007/s11888-017-0373-6 (2017).

29. Testa, U., Pelosi, E. \& Castelli, G. Colorectal cancer: genetic abnormalities, tumor progression, tumor heterogeneity, clonal evolution and tumor-initiating cells. Medical sciences (Basel, Switzerland). 6, 31 https://doi.org/10.3390/medsci6020031 (2018).

30. Hussain, S. \& Hamid, S. Helicobacter pylori in humans: Where are we now? Advanced biomedical research. 3, 63 https://doi.org/10.4103/2277-9175.125844 (2014).

31. Butt, J. \& Epplein, M. Helicobacter pylori and colorectal cancer-A bacterium going abroad? PLoS Pathog. 15, e1007861 https://doi.org/10.1371/journal.ppat.1007861 (2019).

32. Petre, S., Shah, I. A. \& Gilani, N. Review article: gastrointestinal amyloidosis - clinical features, diagnosis and therapy. Aliment. Pharmacol. Ther. 27, 1006-1016 https://doi.org/10.1111/j.13652036.2008.03682.x (2008).

33. Moshkovskii, S. A. Why do cancer cells produce serum amyloid a acute-phase protein? Biochemistry (Moscow). 77, 339-341 https://doi.org/10.1134/s0006297912040037 (2012). 
34. Schindelin, J. et al. Fiji: an open-source platform for biological-image analysis. Nature methods. 9 , 676-682 https://doi.org/10.1038/nmeth.2019 (2012).

35. Pretorius, E. et al. Both lipopolysaccharide and lipoteichoic acids potently induce anomalous fibrin amyloid formation: assessment with novel Amytracker stains. Journal of the Royal Society, Interface. 15, https://doi.org/10.1098/rsif.2017.0941 (2018).

36. Nilsson, K. P., Lindgren, M. \& Hammarstrom, P. A pentameric luminescent-conjugated oligothiophene for optical imaging of in vitro-formed amyloid fibrils and protein aggregates in tissue sections. Methods in molecular biology (Clifton, N.J.). 849, 425-434 https://doi.org/10.1007/978-1-61779551-0_29 (2012).

37. de Waal, G. M., de Villiers, W. J. S., Forgan, T., Roberts, T. \& Pretorius, E. Colorectal cancer is associated with increased circulating lipopolysaccharide, inflammation and hypercoagulability. Sci. Rep. 10, 8777 https://doi.org/10.1038/s41598-020-65324-2 (2020).

38. Jørgensen, A. S. et al. Using cell nuclei features to detect colon cancer tissue in hematoxylin and eosin stained slides. Cytometry Part A. 91, 785-793 https://doi.org/10.1002/cyto.a.23175 (2017).

39. Li, L. et al. Identification of dirty necrosis in colorectal carcinoma based on multiphoton microscopy. Journal of biomedical optics. 19, 066008 https://doi.org/10.1117/1.jbo.19.6.066008 (2014).

40. Kim, Y. S. \& Ho, S. B. Intestinal Goblet Cells and Mucins in Health and Disease: Recent Insights and Progress. Curr. Gastroenterol. Rep. 12, 319-330 https://doi.org/10.1007/s11894-010-0131-2 (2010).

41. De Wever, O., Demetter, P., Mareel, M. \& Bracke, M. Stromal myofibroblasts are drivers of invasive cancer growth. International journal of cancer. 123, 2229-2238 https://doi.org/10.1002/ijc.23925 (2008).

42. Rogojanu, R. et al. Quantitative Image Analysis of Epithelial and Stromal Area in Histological Sections of Colorectal Cancer: An Emerging Diagnostic Tool. Biomed Res Int 2015, 569071, doi:10.1155/2015/569071 (2015).

43. Conti, J. \& Thomas, G. The role of tumour stroma in colorectal cancer invasion and metastasis. Cancers (Basel). 3, 2160-2168 https://doi.org/10.3390/cancers3022160 (2011).

44. Sis, B. et al. Desmoplasia measured by computer assisted image analysis: an independent prognostic marker in colorectal carcinoma. Journal of clinical pathology. 58, 32-38 https://doi.org/10.1136/jcp.2004.018705 (2005).

45. Yoon, H. H. et al. Intertumoral Heterogeneity of CD3(+) and CD8(+) T-Cell Densities in the Microenvironment of DNA Mismatch-Repair-Deficient Colon Cancers: Implications for Prognosis. Clinical cancer research: an official journal of the American Association for Cancer Research. 25, 125-133 https://doi.org/10.1158/1078-0432.ccr-18-1984 (2019).

46. Amicarella, F. et al. Dual role of tumour-infiltrating T helper 17 cells in human colorectal cancer. Gut. 66, 692 https://doi.org/10.1136/gutjnl-2015-310016 (2017).

47. Mager, D. L. Bacteria and cancer: cause, coincidence or cure? A review. J Trans/ Med. 4, 14-14 https://doi.org/10.1186/1479-5876-4-14 (2006). 
48. van Elsland, D. \& Neefjes, J. Bacterial infections and cancer. EMBO Rep. 19, e46632 https://doi.org/10.15252/embr.201846632 (2018).

49. Yu, L. C. Microbiota dysbiosis and barrier dysfunction in inflammatory bowel disease and colorectal cancers: exploring a common ground hypothesis. Journal of biomedical science. 25,79 https://doi.org/10.1186/s12929-018-0483-8 (2018).

50. Zhao, Y., Wang, F., Chang, D., Han, B. \& You, D. -y. Meta-analysis of different test indicators: Helicobacter pylori infection and the risk of colorectal cancer. International Journal of Colorectal Disease. 23, 875-882 https://doi.org/10.1007/s00384-008-0479-z (2008).

51. Wang, F., Sun, M. Y., Shi, S. L. \& Lv, Z. S. Helicobacter pylori infection and normal colorectal mucosaadenomatous polyp-adenocarcinoma sequence: a meta-analysis of 27 case-control studies. Colorectal Dis. 16, 246-252 https://doi.org/10.1111/codi.12290 (2014).

52. Teimoorian, F., Ranaei, M., Hajian Tilaki, K., Shokri Shirvani, J. \& Vosough, Z. Association of Helicobacter pylori Infection With Colon Cancer and Adenomatous Polyps. Iran J Pathol. 13, 325332 (2018).

53. Nam, J. H. et al. Helicobacter pylori infection is an independent risk factor for colonic adenomatous neoplasms. Cancer causes \& control: CCC. 28, 107-115 https://doi.org/10.1007/s10552-016-0839-x (2017).

54. Lucas, C., Barnich, N., Nguyen, H. T. T. \& Microbiota Inflammation and Colorectal Cancer. International journal of molecular sciences. 18, https://doi.org/10.3390/ijms18061310 (2017).

55. Kim, T. J. et al. Helicobacter pylori infection is an independent risk factor of early and advanced colorectal neoplasm. Helicobacter. 22, e12377 https://doi.org/10.1111/hel.12377 (2017).

56. Papastergiou, V., Karatapanis, S. \& Georgopoulos, S. D. Helicobacter pylori and colorectal neoplasia: Is there a causal link? World J Gastroenterol. 22, 649-658 https://doi.org/10.3748/wjg.v22.i2.649 (2016).

57. Burnett-Hartman, A. N., Newcomb, P. A. \& Potter, J. D. Infectious agents and colorectal cancer: a review of Helicobacter pylori, Streptococcus bovis, JC virus, and human papillomavirus. Cancer epidemiology, biomarkers \& prevention: a publication of the American Association for Cancer Research, cosponsored by the American Society of Preventive Oncology. 17, 2970-2979 https://doi.org/10.1158/1055-9965.epi-08-0571 (2008).

58. Hartwich, A. et al. Helicobacter pylori infection, gastrin, cyclooxygenase-2, and apoptosis in colorectal cancer. Int J Colorectal Dis. 16, 202-210 https://doi.org/10.1007/s003840100288 (2001).

59. Thorburn, C. M. et al. Gastrin and colorectal cancer: a prospective study. Gastroenterology. 115, 275280 https://doi.org/10.1016/s0016-5085(98)70193-3 (1998).

60. Sobhani, I. et al. Chronic endogenous hypergastrinemia in humans: evidence for a mitogenic effect on the colonic mucosa. Gastroenterology. 105, 22-30 https://doi.org/10.1016/0016-5085(93)90006$x(1993)$.

61. Zou, S., Fang, L. \& Lee, M. H. Dysbiosis of gut microbiota in promoting the development of colorectal cancer. Gastroenterology report. 6, 1-12 https://doi.org/10.1093/gastro/gox031 (2018). 
62. Swidsinski, A. et al. Association between intraepithelial Escherichia coli and colorectal cancer. Gastroenterology. 115, 281-286 https://doi.org/10.1016/S0016-5085(98)70194-5 (1998).

63. Martin, H. M. et al. Enhanced Escherichia coli adherence and invasion in Crohn's disease and colon cancer. Gastroenterology. 127, 80-93 (2004).

64. Gagnière, J. et al. Gut microbiota imbalance and colorectal cancer. World journal of gastroenterology. 22, 501-518 https://doi.org/10.3748/wjg.v22.i2.501 (2016).

65. Bonnet, M. et al. Colonization of the human gut by E. coli and colorectal cancer risk. Clinical cancer research: an official journal of the American Association for Cancer Research. 20, 859-867 https://doi.org/10.1158/1078-0432.ccr-13-1343 (2014).

66. Buc, E. et al. High prevalence of mucosa-associated E. coli producing cyclomodulin and genotoxin in colon cancer. PLoS One. 8, e56964 https://doi.org/10.1371/journal.pone.0056964 (2013).

67. Sun, J. \& Kato, I. Gut microbiota, inflammation and colorectal cancer. Genes \& Diseases. 3, 130-143 https://doi.org/10.1016/j.gendis.2016.03.004 (2016).

68. Sears, C. L. \& Garrett, W. S. Microbes, microbiota, and colon cancer. Cell Host Microbe. 15, 317-328 https://doi.org/10.1016/j.chom.2014.02.007 (2014).

69. Jahani-Sherafat, S., Alebouyeh, M., Moghim, S., Ahmadi Amoli, H. \& Ghasemian-Safaei, H. Role of gut microbiota in the pathogenesis of colorectal cancer; a review article. Gastroenterology and hepatology from bed to bench. 11, 101-109 (2018).

70. Raisch, J. et al. Colon cancer-associated B2 Escherichia coli colonize gut mucosa and promote cell proliferation. World journal of gastroenterology. 20, 6560-6572 https://doi.org/10.3748/wjg.v20.i21.6560 (2014).

71. Scanlan, P. D. et al. Culture-independent analysis of the gut microbiota in colorectal cancer and polyposis. Environ. Microbiol. 10, 789-798 https://doi.org/10.1111/j.1462-2920.2007.01503.x (2008).

72. Zhu, G. et al. Lipopolysaccharide increases the release of VEGF-C that enhances cell motility and promotes lymphangiogenesis and lymphatic metastasis through the TLR4- NF-KB/JNK pathways in colorectal cancer. Oncotarget. 7, 73711-73724 https://doi.org/10.18632/oncotarget.12449 (2016).

73. O'Leary, D. P. et al. TLR-4 Signalling Accelerates Colon Cancer Cell Adhesion via NF-KB Mediated Transcriptional Up-Regulation of Nox-1. PLOS ONE. 7, e44176 https://doi.org/10.1371/journal.pone.0044176 (2012).

74. Gutfeld, O. et al. Expression of Serum Amyloid A, in Normal, Dysplastic, and Neoplastic Human Colonic Mucosa: Implication for a Role in Colonic Tumorigenesis. Journal of Histochemistry \& Cytochemistry. 54, 63-73 https://doi.org/10.1369/jhc.5A6645.2005 (2006).

75. Lin, H., Tan, G., Liu, Y. \& Lin, S. -q. The prognostic value of serum amyloid A in solid tumors: a metaanalysis. Cancer Cell Int. 19, 62 https://doi.org/10.1186/s12935-019-0783-4 (2019).

76. Knebel, F. H. et al. Serum amyloid A1 is upregulated in human glioblastoma. Journal of neurooncology 132, 383-391, doi:10.1007/s11060-017-2386-z (2017). 
77. Chami, B. et al. Serum amyloid A receptor blockade and incorporation into high-density lipoprotein modulates its pro-inflammatory and pro-thrombotic activities on vascular endothelial cells. International journal of molecular sciences. 16, 11101-11124 https://doi.org/10.3390/ijms160511101 (2015).

78. Ye, R. D. \& Sun, L. Emerging functions of serum amyloid A in inflammation. Journal of leukocyte biology. 98, 923-929 https://doi.org/10.1189/jlb.3VMR0315-080R (2015).

79. De Buck, M. et al. Structure and Expression of Different Serum Amyloid A (SAA) Variants and their Concentration-Dependent Functions During Host Insults. Curr Med Chem. 23, 1725-1755 https://doi.org/10.2174/0929867323666160418114600 (2016).

80. Lipinski, B. Cancer Wars: Significance of Protein Unfolding in Cancer and Its Inhibition with Natural Amphiphilic Substances. Frontiers in Oncology. 4, https://doi.org/10.3389/fonc.2014.00183 (2014).

81. Chiti, F., Dobson, C. M., Protein \& Misfolding Amyloid Formation, and Human Disease: A Summary of Progress Over the Last Decade. Annu Rev Biochem. 86, 27-68 https://doi.org/10.1146/annurevbiochem-061516-045115 (2017).

82. Kell, D. B. \& Pretorius, E. Proteins behaving badly. Substoichiometric molecular control and amplification of the initiation and nature of amyloid fibril formation: lessons from and for blood clotting. Progress in biophysics and molecular biology. 123, 16-41 https://doi.org/10.1016/j.pbiomolbio.2016.08.006 (2017).

83. Kim, S. \& An, S. S. A. Role of p53 isoforms and aggregations in cancer. Med. (Baltim). 95, e3993e3993 https://doi.org/10.1097/MD.0000000000003993 (2016).

84. Noguti, J. et al. Both the intratumoral immune and microbial microenvironment are linked to recurrence in human colon cancer: results from a prospective, multicenter nodal ultrastaging trial. Oncotarget. 9, 23564-23576 https://doi.org/10.18632/oncotarget.25276 (2018).

\section{Figures}




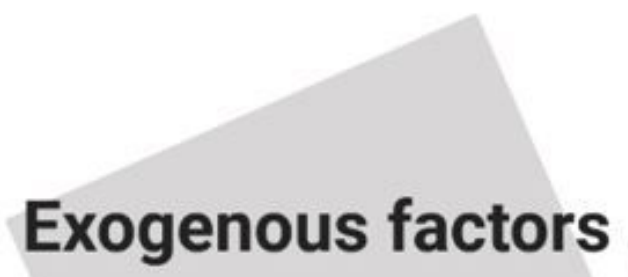

\section{Endogenous factors}

Genetic susceptibility

\section{Environmental insults}

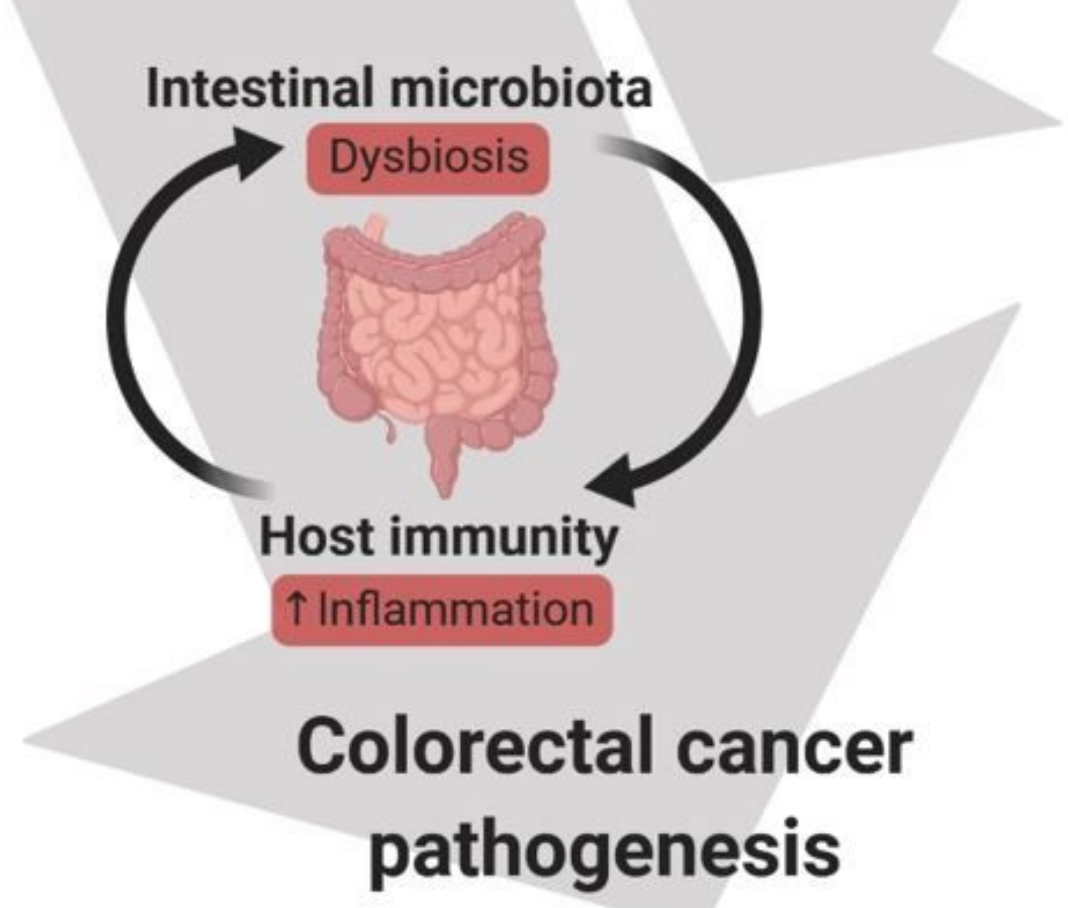

Figure 1

Different aspects that influence colorectal cancer (CRC) pathogenesis, highlighting the involvement of exogenous (environmental) factors. 

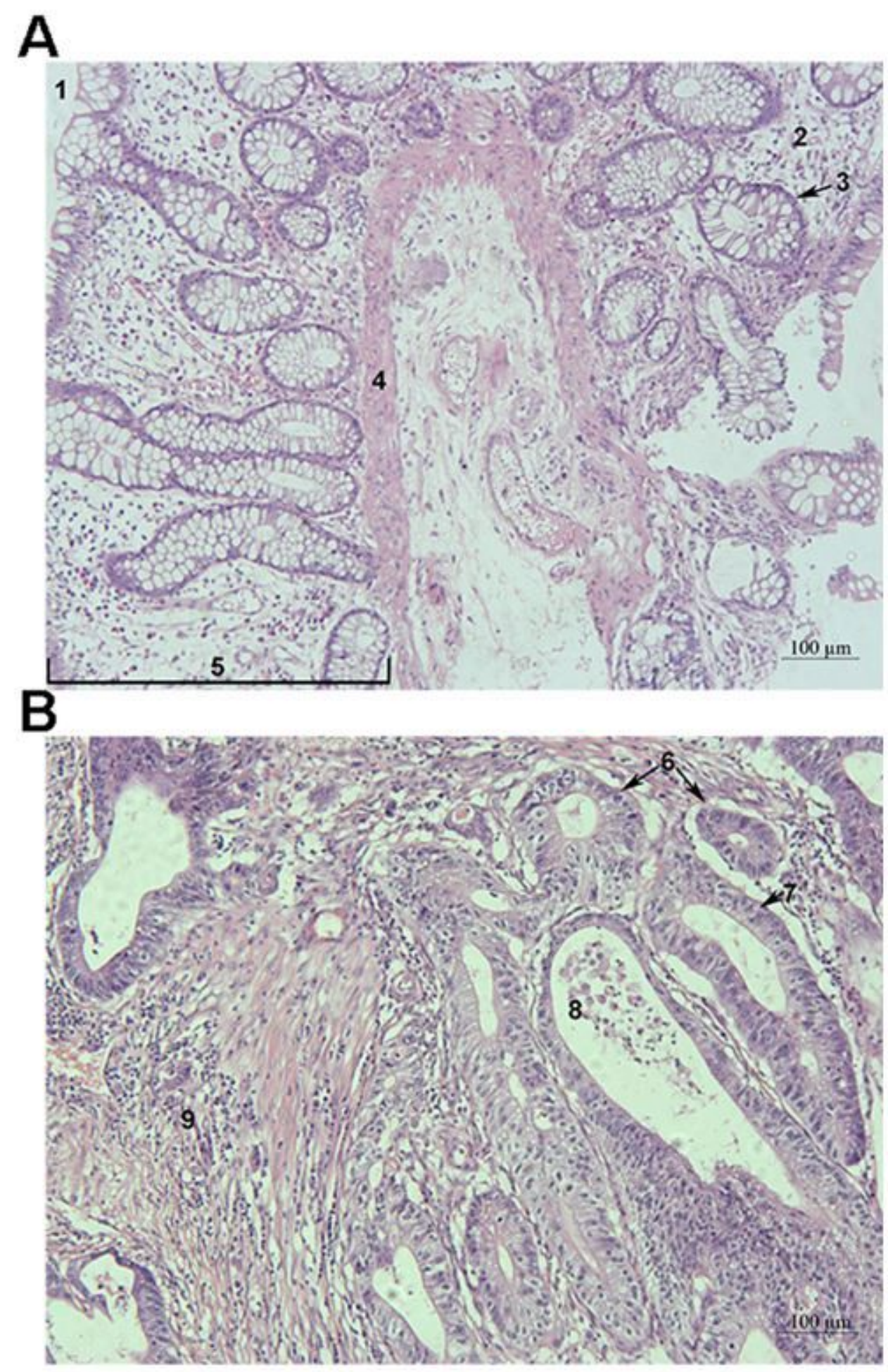

\section{Figure 2}

a) Haematoxylin and eosin (H\&E) stain of healthy colorectal tissue biopsy: 1) lumen, 2) lamina propria (stroma) of mucosa, 3) well-ordered basal nuclei of cuboidal/columnar cells lining the gland, 4) muscularis mucosae, 5) mucosa with glands; b) H\&E stain of colorectal cancer (CRC) tumor tissue: 6) malignant glands of different shapes and sizes, facing in different directions, 7) large nuclei appearing at different levels, 8) necrotic material in the lumen of the gland, 9) tumor stroma with inflammatory cells. 

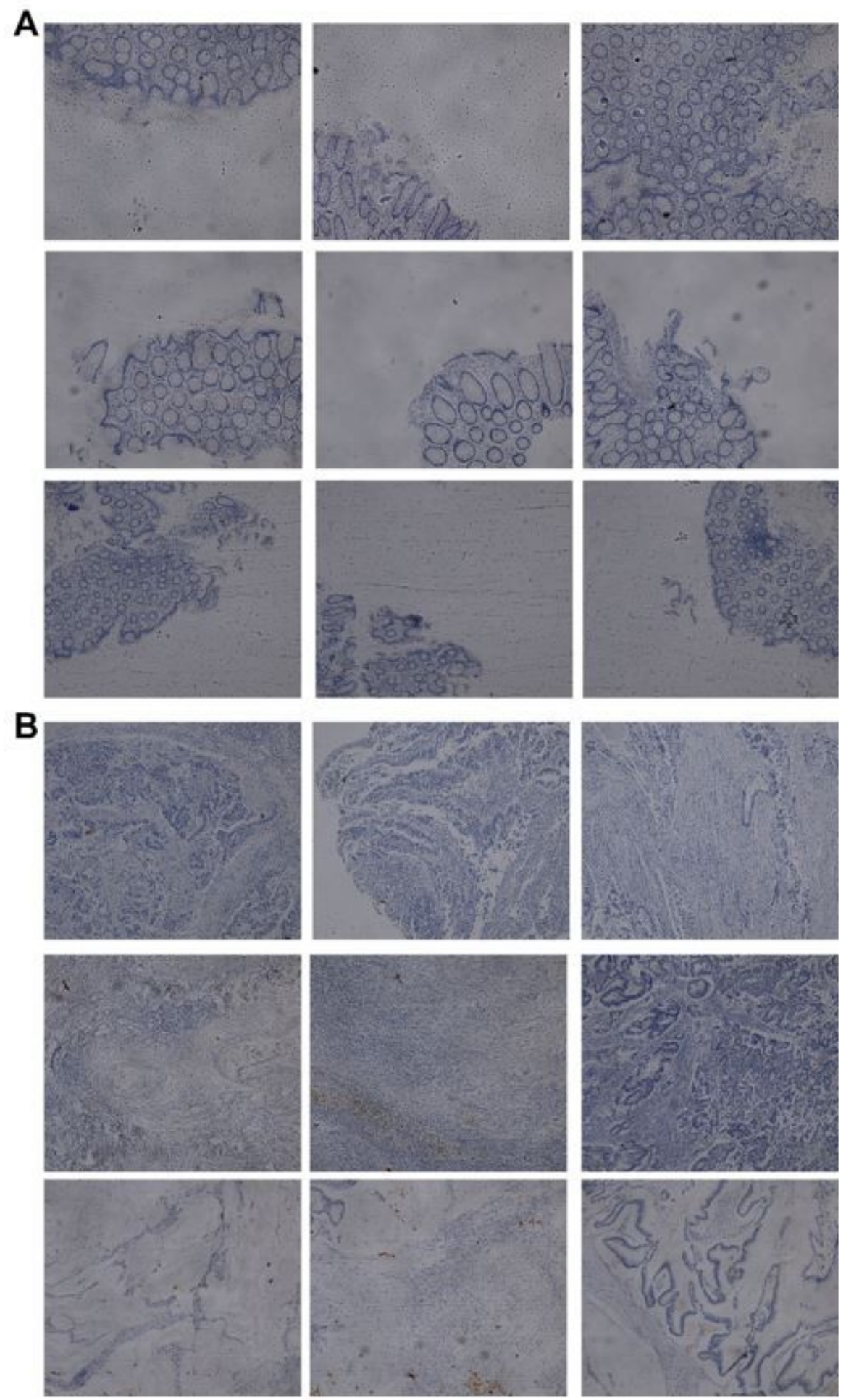

\section{Figure 3}

Representative tile images of a) healthy colorectal tissue biopsies and b) colorectal cancer (CRC) tumor tissues stained with anti-H. pylori antibody. The brightness and contrast of the images were adjusted in Adobe Photoshop CS6. 

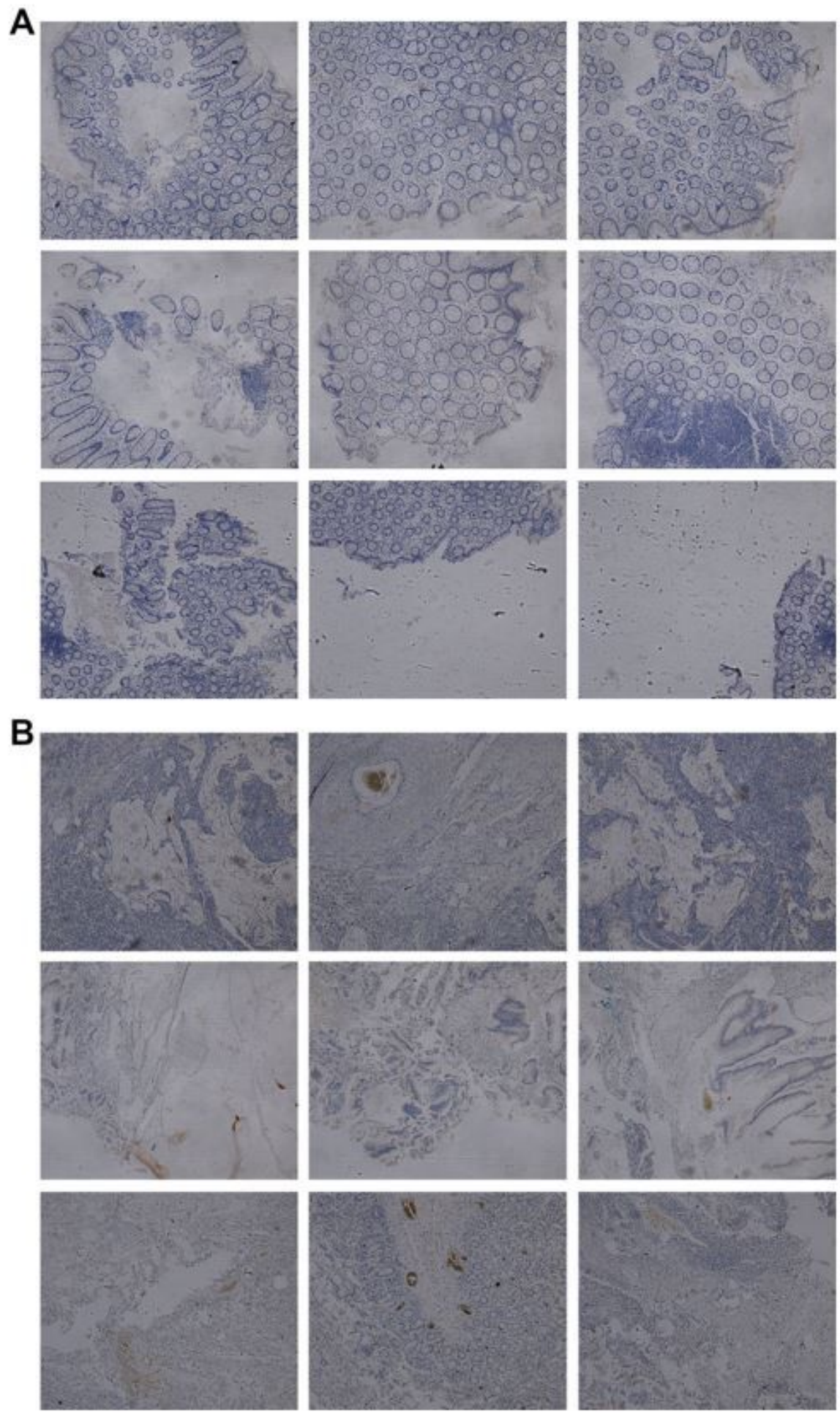

\section{Figure 4}

Representative tile images of a) healthy colorectal tissue biopsies and b) colorectal cancer (CRC) tumor tissues stained with anti-E. coli antibody. The brightness and contrast of the images were adjusted in Adobe Photoshop CS6. 

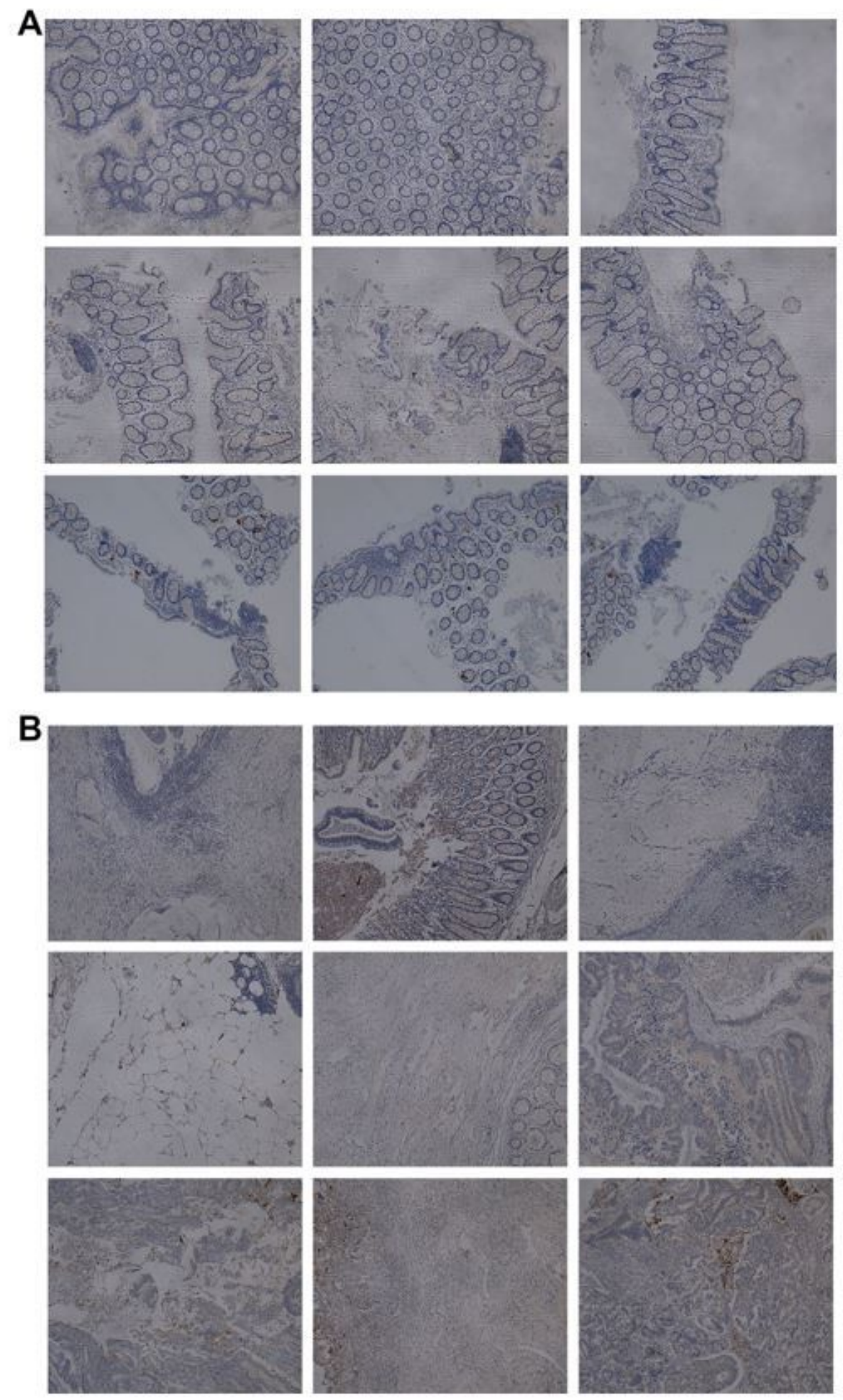

\section{Figure 5}

Representative tile images of a) healthy colorectal tissue biopsies and b) colorectal cancer (CRC) tumor tissues stained with anti-E. coli LPS antibody. The brightness and contrast of the images were adjusted in Adobe Photoshop CS6. 

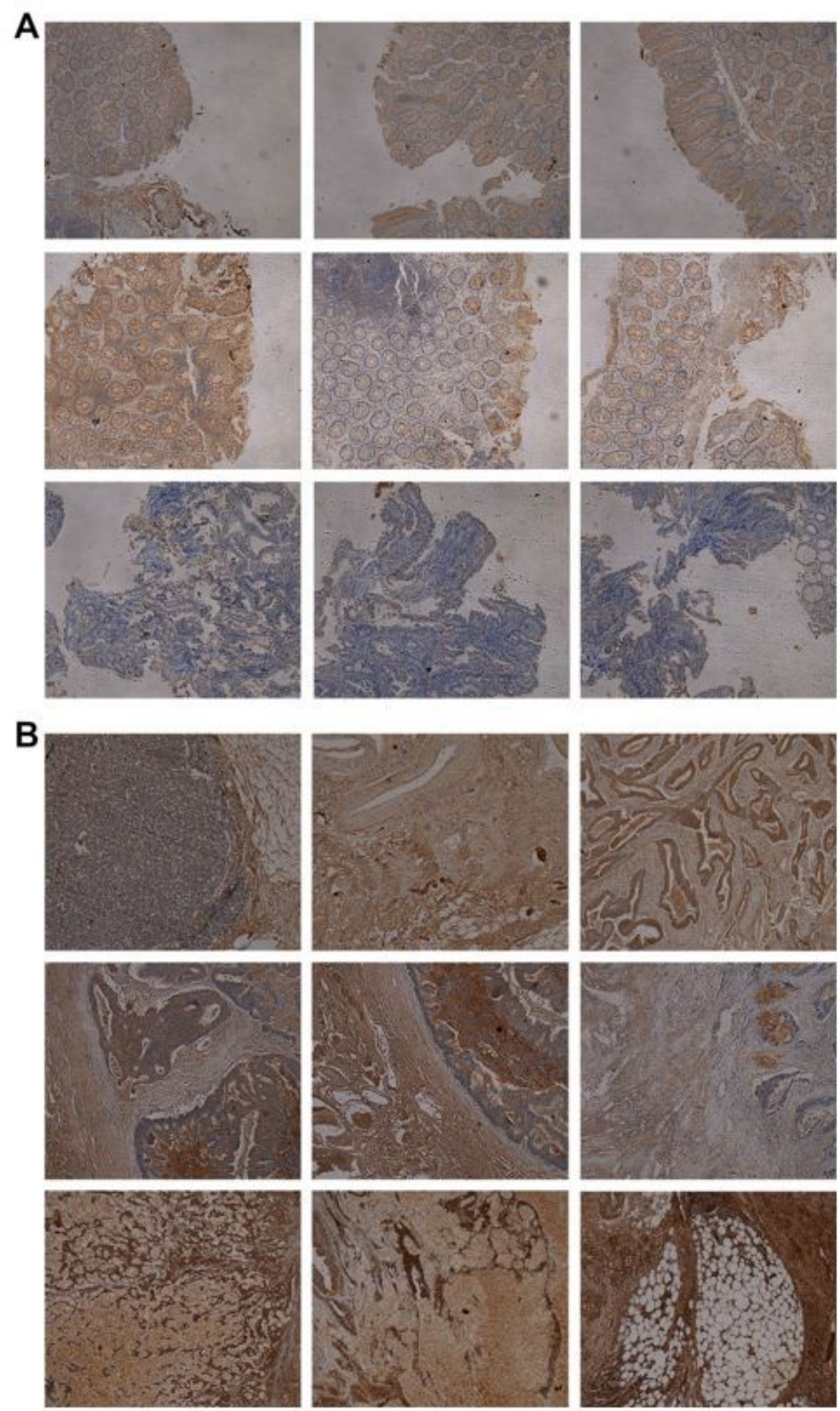

Figure 6

Representative tile images of a) healthy colorectal tissue biopsies and b) colorectal cancer (CRC) tumor tissues stained with anti-SAA antibody. The brightness and contrast of the images were adjusted in Adobe Photoshop CS6. 

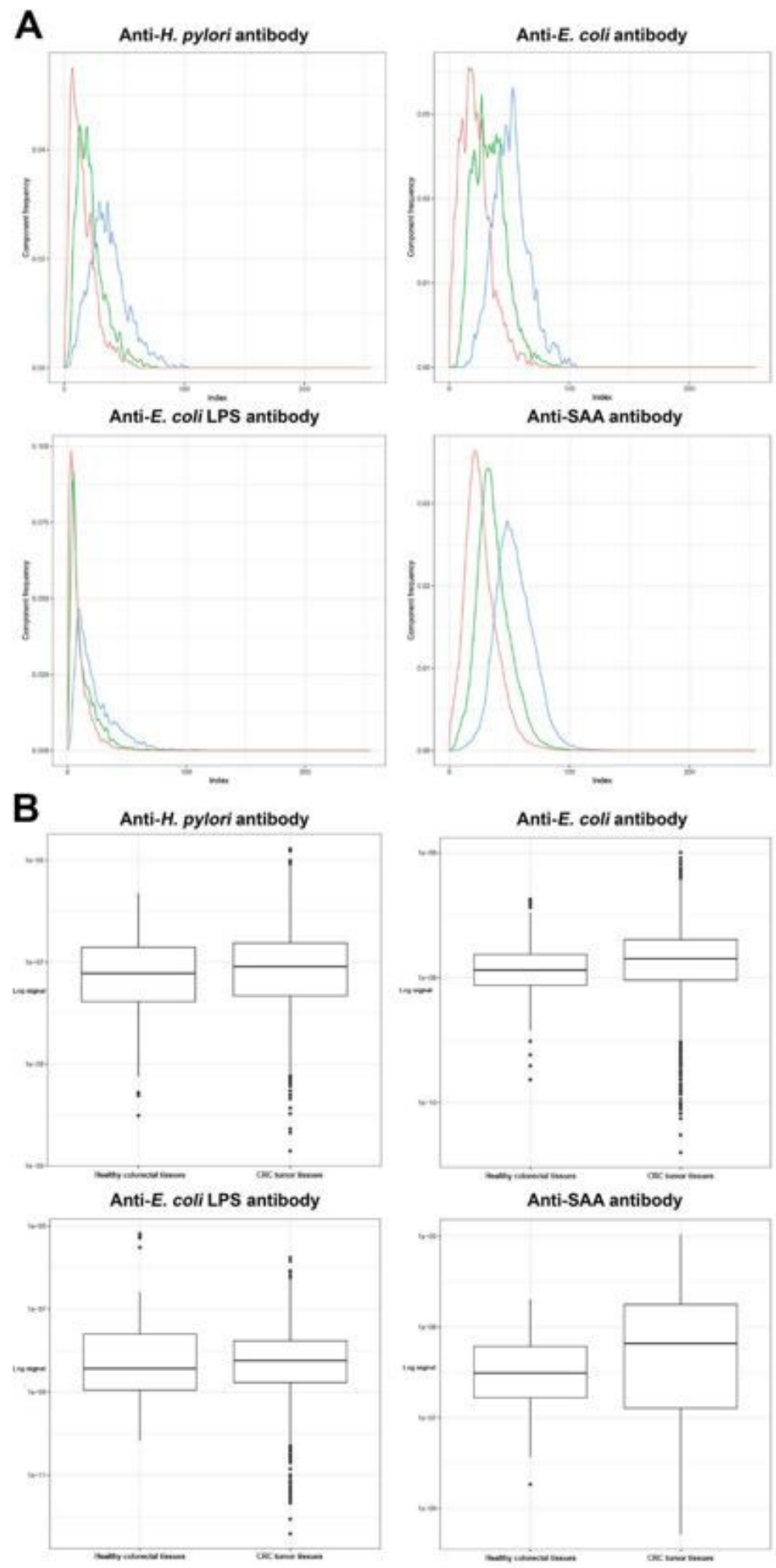

\section{Figure 7}

a) Colour histograms of the positive signal for each antibody based on manually extracted regions of interest across multiple images; b) Box and whisker plots illustrating the distribution of the log signal across antibodies by disease status. 

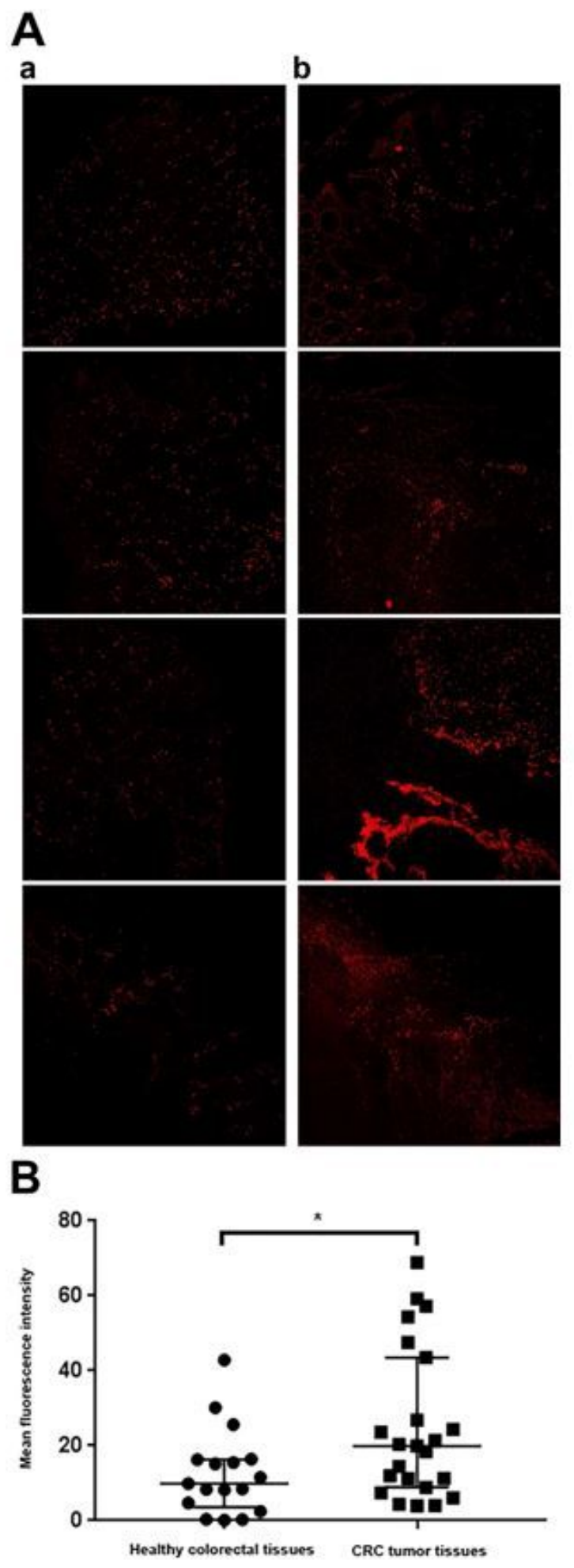

Figure 8

a) Representative confocal micrographs of (A) healthy colorectal tissues and (B) colorectal cancer (CRC) tumor tissues stained with AmytrackerTM 630, showing the amyloid-specific fluorescence signal. The brightness and contrast of the images were adjusted in Adobe Photoshop CS6; b) Scatterplot of the distribution of the mean fluorescence intensities (MFIs) of healthy colorectal tissues $(n=4)$ and CRC 
tumor tissues ( $n=4)$ stained with AmytrackerTM 630 (with the autofluorescence signal subtracted); * $\mathrm{p}<0.05$.

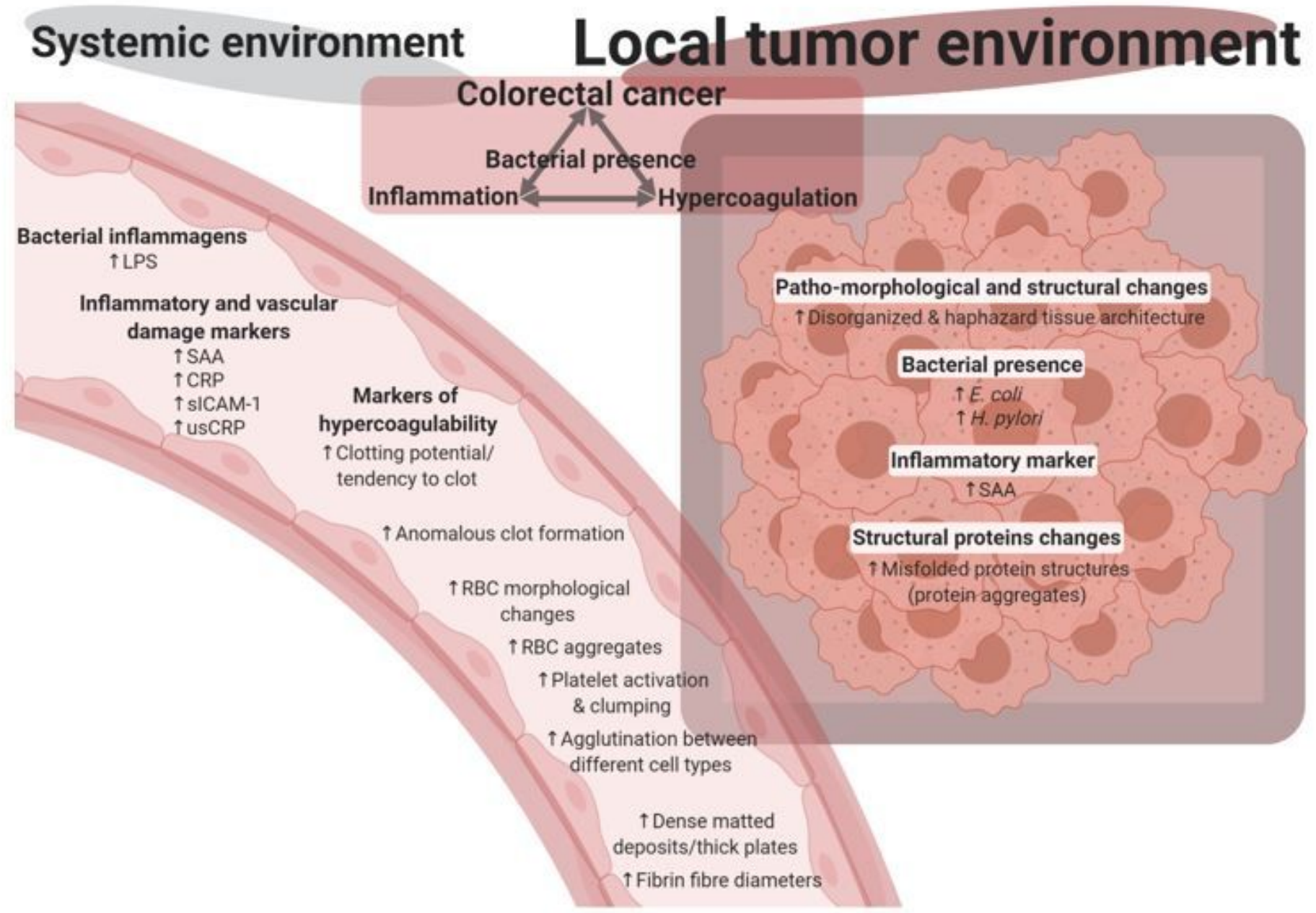

\section{Figure 9}

Summary of findings of the analysis of the local tumor environment, as well as that of the systemic environment of colorectal cancer (CRC) patients, emphasizing the intricate relationship between a bacterial influence, persistent inflammation, hypercoagulation, and colorectal carcinogenesis. Figure made in ()BioRender - https://biorender.com/.

\section{Supplementary Files}

This is a list of supplementary files associated with this preprint. Click to download.

- SupplementaryInformationFINAL.pdf 